\title{
Gallbladder Carcinoma in Association with Ascaris lumbricoides Infection
}

\author{
Robert Lyons and James Schneider
}

\begin{abstract}
Background: Ascaris lumbricoides is a common nematode infection that has not been associated previously with the development of gallbladder carcinoma.

Case Presentation: A 73-year-old Filipino female who had immigrated recently to the United States presented to the emergency department with right upper quadrant abdominal pain associated with nausea and emesis. Her laboratory data were significant for a mild transaminitis and a computed tomography (CT) of the abdomen showed a dilated gallbladder with a non-mobile, heterogenic mass concerning for a gallbladder neoplasm. She underwent open cholecystectomy and was found to have a live Ascaris lumbricoides in her common bile duct. She did well post-operatively and was treated with albendazole for her Ascaris infection.

Discussion: Liver fluke infection has previously been implicated as a cause of biliary carcinoma secondary to chronic inflammation. However, our patient was infected with Ascaris lumbricoides, which has not been associated previously with gallbladder carcinoma. Chronic inflammation from an active Ascaris infection may have contributed to the development of gallbladder carcinoma in a similar manner as is observed with liver fluke infection
\end{abstract}

Keywords: Ascaris; biliary tract; gallbladder carcinoma

G ALLBLADDER CARCINOMA is a rare but noted deadly carcinoma with overall five-year mortality reported to be as high as $80 \%$ depending on the stage at diagnosis [1]. Multiple risk factors for gallbladder carcinoma have been identified and include age, smoking, and presence of gallstones [1,2]. One infectious cause that has been associated with an increased risk of gallbladder carcinoma is infection with the liver flukes Clonorchis sinensis and Opisthorchis viverrini [1]. This is believed to be from chronic inflammation of the biliary tract.

Although liver fluke infection has been associated with the development of biliary cancer, infection with nematodes, such as Ascaris, has not been described previously. Ascaris is a common nematode worldwide, with a reported infection rate of 1.2 million [3]. Infection with Ascaris ranges from asymptomatic to abdominal pain secondary to bowel obstruction $[4,5]$. On review of the literature, we were unable to identify any infection with Ascaris in association with gallbladder carcinoma. We herein report a case of concomitant Ascaris infection and gallbladder carcinoma.

\section{Case Presentation}

We present the case of a 73-year-old Filipino female who presented to the emergency department with a four-day history of worsening right upper quadrant abdominal pain associated with nausea and emesis. She had immigrated recently to the United States from the Philippines. On examination, she was noted to have normal vital signs. She exhibited abdominal tenderness in the right upper quadrant without guarding but was noted to have a negative Murphy sign. Her laboratory data revealed a normal white blood cell count. Her liver function tests revealed a mild transaminitis with an aspartate aminotransferase (AST) and an alanine aminotransferase (ALT) of 118 and 118, respectively, and an alkaline phosphatase of 269 . Her bilirubin was normal. Computed tomography (CT) of the abdomen and pelvis as well as an abdominal ultrasound showed a dilated gallbladder with a non-mobile, heterogenic mass concerning for a gallbladder neoplasm (Fig. 1). Her common bile duct was dilated to $1.5 \mathrm{~cm}$. She was admitted for rehydration and pre-operative

Department of Surgery, Eastern Virginia Medical School, Norfolk, Virginia.

(c) Robert Lyons and James Schneider. 2017; Published by Mary Ann Liebert, Inc. This Open Access article is distributed under the terms of the Creative Commons License (http://creativecommons.org/licenses/by/4.0), which permits unrestricted use, distribution, and reproduction in any medium, provided the original work is properly credited. 


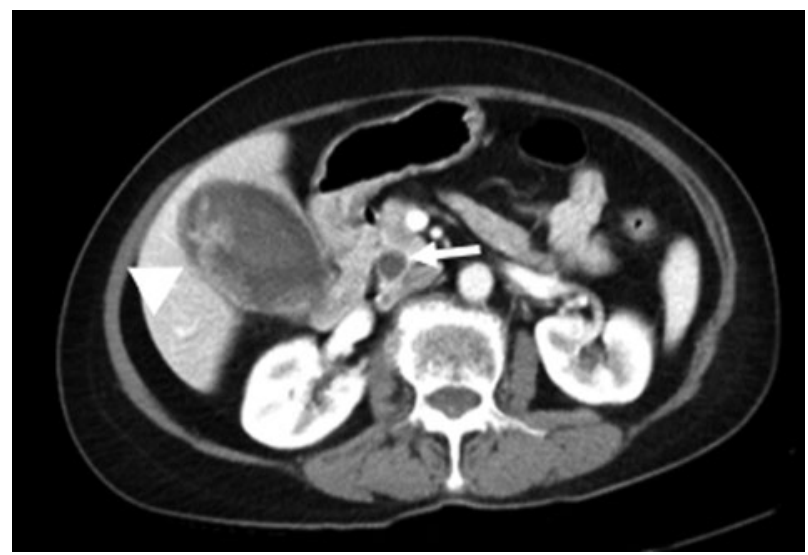

FIG. 1. Axial computed tomography (CT) showing dilated heterogeneous gallbladder (arrowhead) with distended common bile duct (arrow)

medical clearance. A magnetic resonance cholangiopancreatography (MRCP) was obtained that correlated with the CT findings and did not show invasion of the mass into the liver. Tumor markers CA-19-9 and CEA were also obtained and were normal.

The patient was brought subsequently to the operating room for a radical cholecystectomy. This was attempted laparoscopically initially but was soon converted to an open procedure given the inability to retract the gallbladder cephalad. Her gallbladder was thickened and woody in appearance. After transection of her cystic duct, inspection of the common bile duct revealed an intra-luminal entity that resembled a worm (Fig. 2). There was no evidence of hepatic invasion and intra-operative frozen sections were negative for malignancy. The patient did well after surgery and was discharged home on post-operative day five.

The patient's pathology returned as T1bN0 gallbladder carcinoma with negative margins. The common bile duct intra-luminal mass was a female Ascaris lumbricoides. The patient was treated subsequently with a course of albendazole for the nematode infection.

\section{Discussion}

We present the concomitant presence of gallbladder carcinoma and Ascaris lumbricoides infection. Although chronic infection with liver flukes such as Clonorchis sinensis and Opisthorchis viverrini is a known risk factor for the development of cholangiocarcinoma, the documented association between the nematode Ascaris lumbricoides and cholangiocarcinoma or gallbladder carcinoma is not well documented $[1,6,7]$. We were unable to identify any cases of gallbladder carcinoma and Ascaris infection and thus, we believe this is the first reported case of gallbladder carcinoma associated with Ascaris lumbricoides infection.

Adult Ascaris species live primarily in the duodenum or proximal jejunum and can grow to up to $35 \mathrm{~cm}$ in length $[8,9]$. The organism is transmitted via the fecal-oral route [10,11]. Once the eggs are ingested, they hatch in the intestine of the host organism $[10,11]$. The larvae then penetrate the mucosa and invade the blood stream $[10,11]$. This allows the larvae to be carried to the lung where they undergo the next stage of
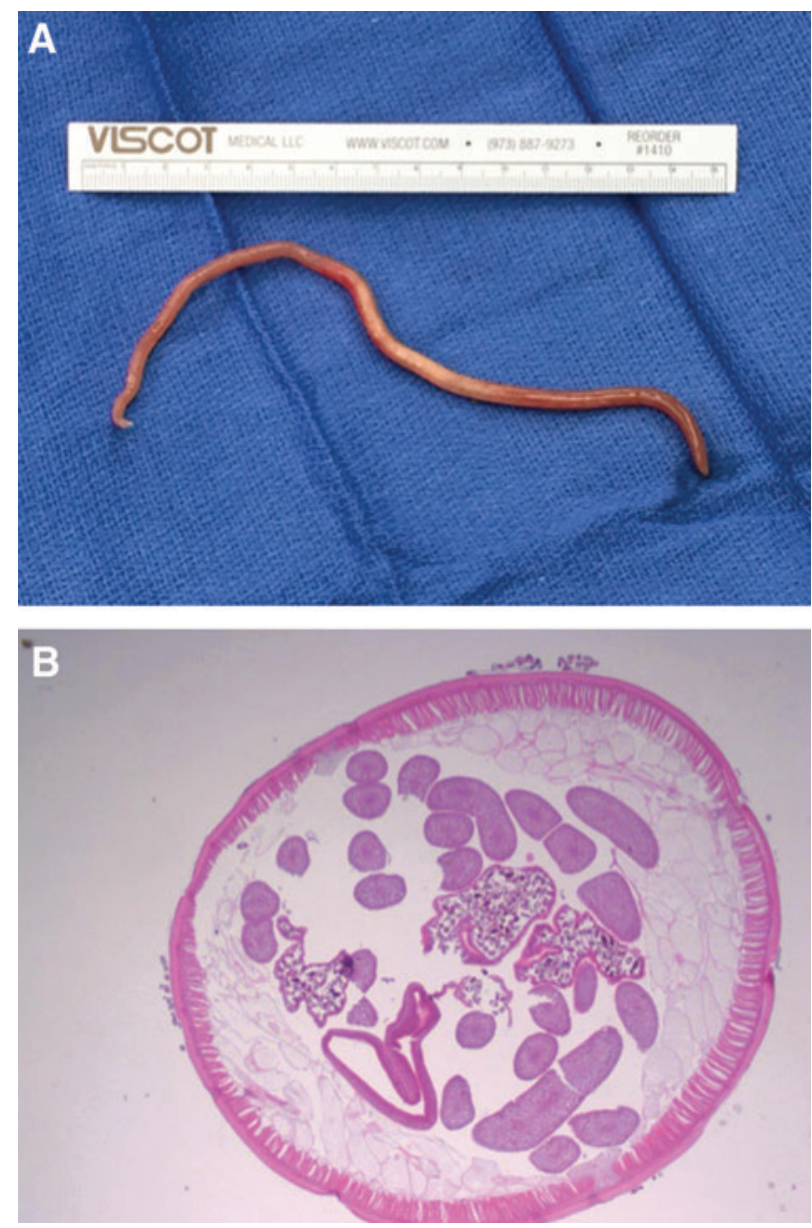

FIG. 2. Ex vivo image of Ascaris lumbricoides (A) and cross-sectional image after hematoxylin and eosin (H\&E) staining (B).

their life cycle and mature in the alveolar capillaries [10,11]. Their presence stimulates respiratory clearance mechanisms allowing for the larvae to move to the epiglottis where they are then commonly swallowed and re-enter the small intestine to complete their development to adulthood before being passed in the host's stool $[8,9]$.

Ascaris infections are usually asymptomatic, but a large burden of infection may result in abdominal pain, especially if there is intestinal obstruction [5]. Ascaris has been noted to infect other sites including the bile duct, liver, and appendix $[5,8,12]$. There are a few case reports of Ascaris infection and associated extra-hepatic cholangiocarcinoma $[6,13]$. The inflammatory response to infection may lead to an increased risk of cholangiocarcinoma in a similar manner as is observed with liver fluke infection [1,8]. We suspect that chronic inflammation of the biliary tree may also contribute to the development of gallbladder carcinoma. In the United States, Ascaris infection is uncommon, with some studies suggesting as low as $2 \%$ of the population [11]. Our patient had recently immigrated from an area in which Ascaris is endemic, and the reported infection rate ranges from $25 \%-75 \%$ of the population $[10,14,15]$.

To our knowledge, this is the first reported case of gallbladder carcinoma with concomitant Ascaris lumbricoides 
infection. Our patient presented with symptoms of gallbladder carcinoma, and only during the operation was her infection identified. We hypothesize that the chronic inflammatory state from her helminth infection likely contributed to the development of her gallbladder carcinoma. Although uncommon, the clinician should be aware of such concomitant infections, especially in patient populations in which helminth infection is high as demonstrated in our patient.

\section{Author Disclosure Statement}

No competing financial interests exist.

\section{References}

1. Augustine MM, Fong Y. Epidemiology and risk factors of biliary tract and primary liver tumors. Surg Oncol Clin North Am 2014;23:171-188.

2. Rustagi T, Dasanu CA. Risk factors for gallbladder cancer and cholangiocarcinoma: Similarities, differences, and updates. J Gastrointest Cancer 2012;43:137-147.

3. Bethony J, Brooker S, Albonico M, et al. Soil-transmitted helminth infections: Ascariasis, trichuriasis, and hookworm. Lancet 2006;367:1521-1532.

4. Seltzer E, Barry M, Crompton DWT. Ascariasis. In: Guerrant RL, Walker DH, Weller PF (eds). Tropical Infectious Diseases. Principles, Pathogens and Practice, 2nd ed. Philadelphia, PA: Elsevier, 2006: 1257-1264

5. Ochoa B. Surgical complications of ascariasis. World J Surg 1991;15:222-227.

6. Lim KG, Sellaiah SP. Biliary ascariasis and extrahepatic cholangiocarcinoma: A report of two cases. Singapore Med J 1994;35:400-402

7. Al-Karawi M, Sanai FM, Yasawy MI, Mohammed AE. Biliary strictures and cholangitis secondary to ascariasis: Endoscopic management. Gastrointest Endosc 1999;50:695697.

8. McPherson P. Medical parasitology In: Henry's Clinical Diagnosis and Management by Laboratory Methods. St. Louis, MO: Elsevier, 2017, pp. 1231-1238.

9. John DT, Petri WA. Markell and Voeg's Medical Parasitology. Philadelphia, PA: Saunders Elsevier, 2006.
10. Flavell DJ. Liver-fluke infection as an aetiological factor in bile-duct carcinoma of man. Trans R Soc Trop Med Hyg 1981;75:814-824.

11. Tietze PE, Tietze PH. The roundworm, Ascaris lumbricoides. Prim Care 1991;18:25.

12. Jones JE. The royal roundworm: Ascaris lumbricoides. J Fam Pract 1981;13:271.

13. Kumar V, Goud U, Pandey D. Distal cholangiocarcinoma with coexistent biliary ascariasis. Ind J Surg 2011;73:366367.

14. Hall A, Holland C. Geographical variation in Ascaris lumbricoides fecundity and its implications for helminth control. Parasitol Today 2000;16:540-544.

15. Cabrera BD. Reinfection and infection rates of ascariasis in relation to seasonal variation in the Philippines. Southeast Asian J Trop Med Public Health 1984;15:394-401.

Address correspondence to: Dr. Robert Lyons Department of Surgery Eastern Virginia Medical School 825 Fairfax Ave, Suite 610 Norfolk, VA 23507

E-mail: lyonsr@evms.edu

$\begin{aligned} & \text { Abbreviations Used } \\ & \mathrm{ALT}=\text { alanine aminotransferase } \\ & \mathrm{AST}=\text { aspartate aminotransferase } \\ & \mathrm{CT}=\text { computed tomography } \\ & \mathrm{H} \& \mathrm{E}= \text { hematoxylin and eosin } \\ & \mathrm{MRCP}=\text { magnetic resonance } \\ & \text { cholangiopancreatography }\end{aligned}$

Cite this article as: Lyons R, Schneider J (2017)

Gallbladder carcinoma in association with Ascaris lumbricoides infection. Surgical Infections Case Reports 2:1, 52-54, DOI: 10.1089/crsi.2017.0009 